\title{
Long-term Trends in Primary Sites of Gastric Adenocarcinoma in Japan and the United States
}

\author{
Michitaka Honda ${ }^{1,2 凶}$, Sandra L. Wong 3,4 , Mark A. Healy ${ }^{4}$, Toshifusa Nakajima ${ }^{5}$, Masayuki Watanabe ${ }^{5}$ \\ Shingo Fukuma ${ }^{6}$, Shunichi Fukuhara', and John Z. Ayanian 7,8 \\ 1. Department of Minimally Invasive Surgical and Medical Oncology, Fukushima Medical University, Fukushima, Japan \\ 2. Department of Surgery, Southern TOHOKU Research Institute for Neuroscience, Southern TOHOKU General Hospital \\ 3. Department of Surgery, Geisel School of Medicine and Dartmouth-Hitchcockand Medical Center, Lebanon, NH, USA \\ 4. Department of Surgery and Center for Healthcare outcomes and Policy, University of Michigan, Ann Arbor, MI, USA \\ 5. Department of Gastroenterological Surgery, Gastroenterological Center, Cancer Institute Hospital, Japanese Foundation for Cancer Research, Tokyo, Japan \\ 6. Department of Healthcare Epidemiology, Graduate School of Medicine and Public Health, Kyoto University, Kyoto, Japan \\ 7. Institute for Healthcare Policy and Innovation, University of Michigan, Ann Arbor, MI, USA \\ 8. Division of General Medicine, University of Michigan Medical School, Ann Arbor, MI, USA \\ $\square$ Corresponding author: Michitaka Honda M.D. Ph.D., Department of Minimally Invasive Surgical and Medical Oncology, Fukushima Medical University, 1 \\ Hikarigaoka, Fukushima 960-1295, Japan. Telephone: 81-24-547-1111; Fax: 81-24-922-5320; E-mail: mhonda@fukushimamed.com \\ (c) Ivyspring International Publisher. This is an open access article distributed under the terms of the Creative Commons Attribution (CC BY-NC) license \\ (https://creativecommons.org/licenses/by-nc/4.0/). See http://ivyspring.com/terms for full terms and conditions.
}

Received: 2017.01.14; Accepted: 2017.04.26; Published: 2017.07.05

\begin{abstract}
Background: The incidence and characteristics of gastric cancer have been shown to vary widely across Western and Eastern countries. Our study had two aims: to evaluate long-term trends in gastric adenocarcinoma in Japan over a period of 70 years, and to anticipate the future of gastric cancer in Japan, through comparison with data from the United States.

Methods: Japanese patient data for 19,306 incident cases of gastric adenocarcinoma from $1946-$ 2014 were collected from the Gastric Cancer Database at the Cancer Institute Hospital, Tokyo, Japan (CIH-GCDB). U.S. patient data for 78,625 incident cases of gastric cancer from 1973 - 2012 were obtained from the National Cancer Institute's Surveillance, Epidemiology, and End Results (SEER) database. Changes over time in patient and tumor characteristics were investigated in these two cohorts.

Results: There was a marked reduction of cancer incidence in the lower third of the stomach in the CIH-GCDB; over $70 \%$ to around $30 \%$. The incidence in the upper third has been increasing steadily over time; $3 \%$ to $19 \%$, although the number of cardia tumors has not changed. An increase in elderly and obese patients was also noted. In the U.S. population, there was a significant difference in the primary site across races. A notable overall increase in cardia cancer was evident in the Western population during the study period, with no similar change evident in the Japanese population over the last 15 years. In the East Asian population, the proportional frequency of tumors in the cardia was lower and that of tumors in the pyloric antrum was higher.

Conclusion: In Japan, cancer in the antrum or pylorus of the stomach has been declining, whereas cancer in the body has been increasing. Unlike the Western population in the United States, adenocarcinoma of esophago-gastric junction is not increasing in Japan.
\end{abstract}

Key words: gastric cancer, primary site, long-term trend

\section{Background}

The incidence rates of gastric cancer have been shown to vary widely across countries $(1,2)$. The highest incidence rates are in East Asia (particularly Japan, China, Mongolia and Korea) and some parts of
South America, whereas the lowest rates are in North America. Over the last quarter of a century, there has been a steady decline in the age-adjusted incidence rate of gastric cancer in Japan (3-5), and also in other 
developed countries of North America and Europe $(4,6,7)$ (Figure 1A). These trends may be attributable to a reduced intake of foods preserved by salting or smoking, and a reduction in the prevalence of $H$. pylori infection (8-10) through improvements in hygiene $(3,9,11-14)$. However, a steady increase in the estimated number of new patients with gastric cancer has been observed in Japan with the rapid aging of society (Figure 1B) (15).

Under these circumstances, the oncological characteristics of stomach cancer have been changing. Namely, the increasing incidence of adenocarcinoma in the cardia has been strongly associated with the increase of obesity and gastro-esophageal reflux disease followed by the development of Barrett's esophagus in western countries (16-18). Under the influence of lifestyle "Westernization," there are also concerns that a rapid increase of adenocarcinoma in the EGJ will become evident in the near future in East
Asia $(15,19,20)$, whereas cancer at the EGJ has remained rare (21-23). As some previous reports have noted, there are distinct differences in the primary site and biologic characteristics of gastric cancer between Asian patients and those from other racial and ethnic groups (24-26). Although some researchers have previously investigated differences in gastric cancer between white and black or Hispanic and nonHispanic patients using national databases in the U.S. $(25,27,28)$, few studies focused on the Asian population have been published recently.

This present study was conducted to delineate the near future of gastric cancer in East Asia, through comparison of the long-term trends of gastric cancer subsites between Japanese patients and the East Asian population of a national database in the U.S. Our objectives were to provide relevant information that would allow clinicians to consider suitable treatment strategies and to guide planning of clinical research.

A. Age-adjusted incidence rate and death rate of gastric cancer

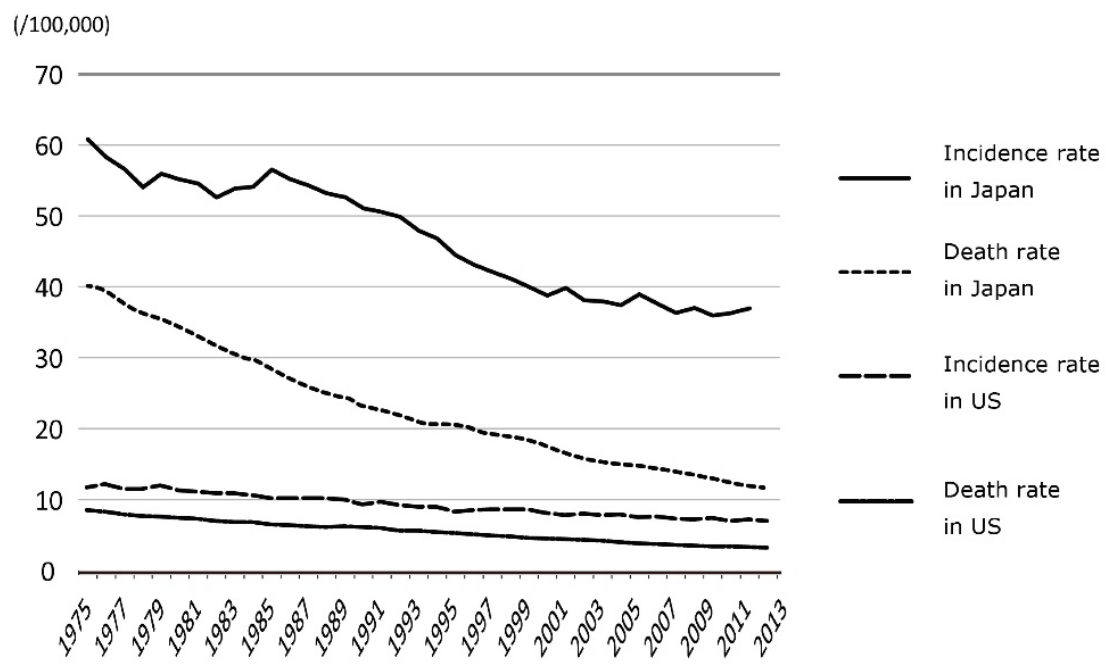

B. Number of new cases with gastric cancer in whole of Japan

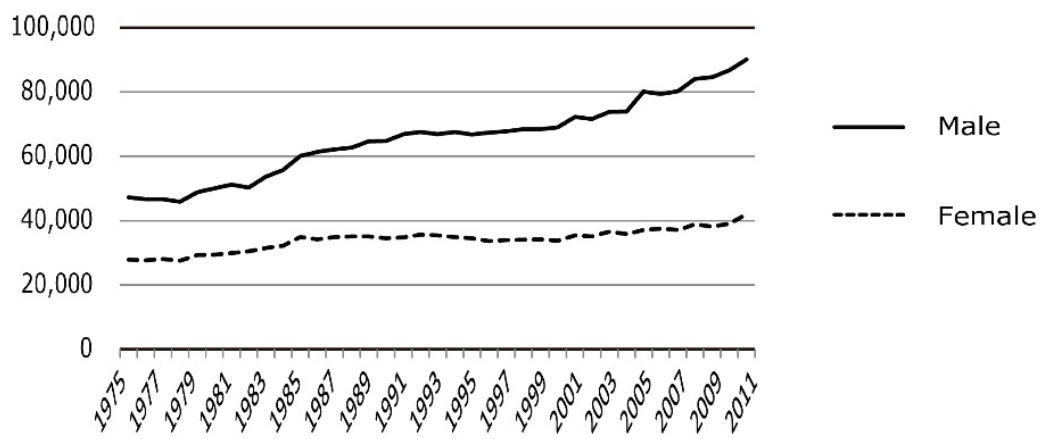

Figure 1: Age-adjusted incident rate and death rate of Gastric cancer in Japan and the U.S. A: Age-adjusted incident rate of gastric cancer on Japanese and U.S. national statistics. Citation from Cancer Registry and Statistics, Cancer Information Service, National Cancer Center in Japan (6) and World Health Organization, GLOBOCAN 2012(7). B: Estimated number of new gastric cancer patients by gender in Japan. Citation from Cancer Registry and Statistics, Cancer Information Service, National Cancer Center in Japan (6) 


\section{Methods}

\section{Cohort Selection}

Data for Japanese patients were identified from the Gastric Cancer Database at the Cancer Institute Hospital, Tokyo, Japan (CIH-GCDB) (29). The database includes entries for 19,306 consecutive patients who were treated for gastric cancer between 1946 and 2014 in the department of surgery at the institute. Patients who received only endoscopic resection or treated by the chemotherapy without any surgical interventions were originally excluded in CIH-GCDB. In addition, patients with histologically proven squamous cell carcinoma, adenosquamous carcinoma or non-epithelial tumors such as lymphoma, sarcoma and metastatic cancers from other primary neoplasms were excluded from the present analyses. Patient data were completely anonymized.

Data for patients in the U.S. were obtained from the National Cancer Institute's Surveillance, Epidemiology, and End Results (SEER) database. The SEER database is a population-based publicly available data set that has been gathering data since 1973 and represents approximately $28 \%$ of all cancer cases in the U.S. After excluding histologically proven squamous cell carcinoma, sarcoma and lymphoma, a total of 78,625 patients who were diagnosed as having gastric cancer between 1973 and 2012 were enrolled. Because the data from both the SEER registry (http:/ / seer.cancer.gov/) and the CIH-GCDB (29) are de-identified and publicly available, no institutional review board approval was necessary for this study.

\section{Definition of the primary site}

There is a difference in primary tumor anatomical subsite classification between the two databases (Supplemental Figure 1). The tumor location data in SEER are coded using the International Classification of Diseases for Oncology, 3rd edition (ICD-O-3) (30), whereas they are coded according to the classification of the Japanese Gastric Cancer Association (JGCA) (31) in the CIH-GCDB, being divided anatomically into three stomach regions, i.e. the upper, middle, and lower thirds defined by the lines connecting the trisected points on the lesser and greater curvatures. In addition, the area extending $2 \mathrm{~cm}$ above to $2 \mathrm{~cm}$ below the esophago-gastric junction (EGJ) is designated the EGJ area. Tumors having their epicenter in this area are designated as EGJ carcinomas. In order to account for the different anatomical subsite classifications across databases, we treated the "cardia" as synonymous with the "EGJ", the "body and fundus" as synonymous with the "upper third and middle third" and the "antrum and pylorus" as synonymous with the lower third in the JGCA data.

\section{Study variables}

Patient-level data, including gender, age at diagnosis, ethnicity, tumor primary site or location, tumor size, TNM staging and histology were identified from each of the CIH-GCDB and SEER databases. To investigate the shifts in tumor location over time, the proportional frequencies in the CIH-GCDB were calculated every ten years, and those in the SEER every five years. As potential confounders for the primary site, patient ages, gender and body mass index (BMI) were obtained for the Japanese population. The $7^{\text {th }}$ edition of the American Joint Committee on Cancer (AJCC) TNM classification was used for tumor staging based on CIH-GCDB data, whereas tumor staging was made on the basis of the $6^{\text {th }}$ edition of the AJCC TNM staging system for part of the SEER database (from 2004 to 2012, n=18,092).

\section{Statistical analysis}

The descriptive statistics were evaluated with reference to the patients' backgrounds and tumor characteristics and, as necessary, continuous variables were compared using Student's $t$ test and categorical variables by Fisher's exact test.

To estimate the odds ratio of adenocarcinoma occurring in the upper third of the stomach, logistic regression models were analyzed with the time period as a dependent variable and incidence of cancer in the upper third of the stomach as an independent variable. In addition, to compare time trends among white and black Americans, East Asian Americans (Japanese $=4,320$, Chinese $=2,008$ and Koreans $=874$ ) living in the US, and Japanese patients entered in the CIH-GCDB. All statistical tests were two-sided, and $p$ values of 0.05 or less were considered to indicate statistical significance. All the analyses were performed with STATA version 11.1 (Stata Corp, College Station, TX).

\section{Results}

\section{Japanese population in the CIH-GCDB}

Table 1 shows the characteristics of the patients and their tumors in Japan. The mean patient age was 59.0 years, and the proportion of males was $65.2 \%$. Figure 2A shows the change over time in the proportion of tumors according to the primary site for every ten-year period from 1946 to 2014. There was a marked reduction of cancer incidence in the lower third of the stomach, whereas incidence in the upper third has been increasing steadily up to the present. The proportion of EGJ cancers was found not to have changed markedly during the observation period. On 
the basis of Figure 2A, we divided the study period into three parts: 1946 to 1974 as the early period, 1975 to 1994 as the middle period, and 1995 to 2014 as the late period. Table 1 also shows the characteristics in each group. The mean age and BMI of patients at diagnosis has been increasing over time, but there have not been any significant changes in the gender ratio, histological types or cross-sectional position. Besides, the proportion of signet-ring cell carcinoma had been increasing from early to middle period.

Table 1. Patients and tumor characteristics and the time trend in $\mathrm{CIH}-\mathrm{GCDB}$

\begin{tabular}{|c|c|c|c|c|c|c|c|c|c|}
\hline & \multicolumn{2}{|c|}{ All Patients } & \multicolumn{2}{|c|}{1946 to 1974} & \multicolumn{2}{|c|}{1975 to 1994} & \multicolumn{3}{|c|}{1995 to 2014} \\
\hline$(\mathrm{N}=)$ & 19,306 & & 5,991 & & 5,437 & & 7,878 & & \\
\hline & No. & $\%$ & No. & $\%$ & No. & $\%$ & No. & $\%$ & $p$ \\
\hline Age at treatment & & & & & & & & & $<.001$ \\
\hline Mean & 59.0 & & 55.1 & & 58.0 & & 62.6 & & \\
\hline SD & 12.0 & & 11.1 & & 11.9 & & 11.6 & & \\
\hline Gender & & & & & & & & & 0.029 \\
\hline Male & 12,584 & 65.2 & 3,827 & 63.9 & 3,599 & 66.2 & 5,158 & 65.5 & \\
\hline Female & 6,702 & 34.7 & 2,164 & 36.1 & 1,838 & 33.8 & 2,700 & 34.3 & \\
\hline BMI $\left(\mathrm{kg} / \mathrm{m}^{2}\right)$ & & & & & & & & & \\
\hline Mean & 21.3 & & 19.8 & & 21.5 & & 22.3 & & \\
\hline SD & 3.2 & & 2.8 & & 2.9 & & 3.3 & & \\
\hline Primary site* & & & & & & & & & $<.001$ \\
\hline EGJ & 1,160 & 6.0 & 457 & 7.6 & 351 & 6.5 & 352 & 4.5 & \\
\hline Upper & 2,571 & 13.3 & 401 & 6.7 & 762 & 14.0 & 1,388 & 17.6 & \\
\hline Middle & 8,229 & 42.6 & 2,102 & 35.1 & 2,621 & 48.2 & 3,506 & 44.5 & \\
\hline Lower & 6,843 & 35.4 & 2,927 & 48.9 & 1,565 & 28.8 & 2,351 & 29.8 & \\
\hline Unclassified & 503 & 2.6 & 104 & 1.7 & 138 & 2.5 & 281 & 3.6 & \\
\hline Tumor size (mm) & & & & & & & & & $<.001$ \\
\hline Mean & 56.4 & & 68.8 & & 55.3 & & 48.5 & & \\
\hline SD & 35.9 & & 29.4 & & 38.6 & & 35.6 & & \\
\hline Stage & & & & & & & & & $<.001$ \\
\hline IA & 6,225 & 32.2 & 714 & 11.9 & 2,080 & 38.3 & 3,431 & 43.6 & \\
\hline IB & 1,483 & 7.7 & 283 & 4.7 & 451 & 8.3 & 749 & 9.5 & \\
\hline IIA & 1,466 & 7.6 & 563 & 9.4 & 353 & 6.5 & 550 & 7.0 & \\
\hline IIB & 1,557 & 8.1 & 630 & 10.5 & 416 & 7.7 & 511 & 6.5 & \\
\hline IIIA & 1,390 & 7.2 & 691 & 11.5 & 308 & 5.7 & 391 & 5.0 & \\
\hline IIIB & 1,428 & 7.4 & 699 & 11.7 & 356 & 6.5 & 373 & 4.7 & \\
\hline IIIC & 1,108 & 5.7 & 498 & 8.3 & 352 & 6.5 & 258 & 3.3 & \\
\hline IV & 3,072 & 15.9 & 1,304 & 21.8 & 754 & 13.9 & 1,014 & 12.9 & \\
\hline Unknown & 1,577 & 8.2 & 609 & 10.2 & 367 & 6.8 & 601 & 7.6 & \\
\hline Histological findin & $\mathrm{gs}^{*}$ & & & & & & & & $<.001$ \\
\hline tub/pap & 7,989 & 41.4 & 2,650 & 44.2 & 2,284 & 42.0 & 3,055 & 38.8 & \\
\hline poor & 5,797 & 30.0 & 1,980 & 33.0 & 1,476 & 27.1 & 2,341 & 29.7 & \\
\hline muc & 482 & 2.5 & 182 & 3.0 & 133 & 2.4 & 167 & 2.1 & \\
\hline sig & 3,299 & 17.1 & 361 & 6.0 & 1,292 & 23.8 & 1,646 & 20.9 & \\
\hline Unknown & 32 & 0.2 & 6 & 0.1 & 2 & 0.0 & 24 & 0.3 & \\
\hline
\end{tabular}

Table 2. Independent risk factors for upper third gastric cancer in $\mathrm{CIH}-\mathrm{GCDB}$

\begin{tabular}{llllll}
\hline & $\begin{array}{l}\text { Odds } \\
\text { Ratio }\end{array}$ & SE & P-value & $\begin{array}{l}\text { 95\% Confidential } \\
\text { Interval }\end{array}$ \\
\hline Gender (Male/Female) & 0.745 & 0.036 & $<0.001$ & $0.678-$ & 0.818 \\
Time proceeds (per year) & 1.019 & 0.016 & $<0.001$ & $1.158-1.222$ \\
$\begin{array}{l}\text { Upper age (every 10 } \\
\text { years) }\end{array}$ & 1.082 & 0.020 & $<0.001$ & $1.043-1.122$ \\
Higher BMI(kg/m2) & 1.036 & $0.007<0.001$ & $1.022-1.050$ \\
\hline BMI; Body Mass Index & & & & &
\end{tabular}

Figure 2B shows the changes in patient age over time, and BMI at diagnosis for each sex. Logistic regression analysis showed that gender (male), age (older), BMI (obese) and period (recent years) were significant independent risk factor for the incidence of upper third gastric cancer (Table 2).

\section{US population in the SEER database}

Table 3 shows the characteristics of the U.S. patients and their tumors. In this comparison between patients as a whole and the East Asian population, there was a significant difference only in the primary site, and there were no clear differences in the other items. In the East Asian population, the proportion of tumors in the cardia was lower $(9.3 \%)$ and that of tumors in the pyloric antrum was higher (29.7\%). Figure 3 shows the trend of the primary site for each of the white, black, and East Asian populations during this period. A notable increase of tumors in the cardia was evident in the white or black population during the study period overall, but no remarkable change was evident in the East Asian population over the last 15 years.

Table 3. Patients and tumor characteristic of All Patients and East Asian patients with gastric cancer in SEER database

\begin{tabular}{|c|c|c|c|c|c|}
\hline \multirow{2}{*}{\multicolumn{2}{|c|}{$(\mathrm{N}=)$}} & \multicolumn{2}{|c|}{ All Patients } & \multicolumn{2}{|c|}{ East Asian } \\
\hline & & 78,625 & $(\%)$ & 7,202 & $(\%)$ \\
\hline \multicolumn{6}{|c|}{ Diagnostic Year } \\
\hline & 1973-1982 & 18,875 & 24.0 & 1,232 & 17.1 \\
\hline & 1983-1992 & 19,847 & 25.2 & 1,793 & 24.9 \\
\hline & 1993-2002 & 19,852 & 25.2 & 2,123 & 29.5 \\
\hline & 2003-2012 & 20,051 & 25.5 & 2,054 & 28.5 \\
\hline \multirow[t]{4}{*}{ Race } & White & 58,118 & 73.9 & N.A. & \\
\hline & Black & 9,251 & 11.8 & & \\
\hline & East Asian & 7,202 & 9.2 & & \\
\hline & Others & 4,054 & 5.2 & & \\
\hline \multicolumn{6}{|c|}{ Age at diagnosis (Year) } \\
\hline & Mean & 69.4 & & 70.5 & \\
\hline & SD & 15.7 & & 13.5 & \\
\hline \multicolumn{6}{|c|}{ Gender } \\
\hline & Male & 48,541 & 61.7 & 4,241 & 58.9 \\
\hline & Female & 30,084 & 38.3 & 2,961 & 41.1 \\
\hline \multicolumn{6}{|c|}{ Primary Site } \\
\hline & Cardia & 18,496 & 23.5 & 673 & 9.3 \\
\hline & Fundus & 3,270 & 4.2 & 189 & 2.6 \\
\hline & Body & 5,268 & 6.7 & 767 & 10.6 \\
\hline & Pylorus or Antrum & 16,490 & 21.0 & 2,361 & 32.8 \\
\hline & Overlapping & 17,380 & 22.1 & 2,061 & 28.6 \\
\hline & NOS & 17,721 & 22.5 & 1,151 & 16.0 \\
\hline \multicolumn{6}{|c|}{ Tumor size (mm) } \\
\hline & Mean & 48.3 & & 49.5 & \\
\hline & SD & 44.8 & & 43.7 & \\
\hline \multicolumn{6}{|c|}{ Histological findings } \\
\hline & well differentiated & 3,851 & 4.9 & 308 & 4.3 \\
\hline & moderate & 14,933 & 19.0 & 1,499 & 20.8 \\
\hline & poor & 33,644 & 42.8 & 3,494 & 48.5 \\
\hline & others & 2,922 & 3.7 & 158 & 2.2 \\
\hline & Unknown & 23,275 & 29.6 & 1,748 & 24.3 \\
\hline \multicolumn{6}{|c|}{ TNM Stage AJCC 6th (Available data from 2004 to 2012) } \\
\hline & $(\mathrm{N}=)$ & 18,092 & $(\%)$ & 1,840 & $(\%)$ \\
\hline & 0 & 182 & 1.0 & 27 & 1.5 \\
\hline & IA & 2,530 & 14.0 & 311 & 16.9 \\
\hline & IB & 1,713 & 9.5 & 198 & 10.8 \\
\hline & II & 1,899 & 10.5 & 194 & 10.5 \\
\hline & IIIA & 1,460 & 8.1 & 156 & 8.5 \\
\hline & IIIB & 324 & 1.8 & 46 & 2.5 \\
\hline & IV & 6,760 & 37.4 & 668 & 36.3 \\
\hline & Unknown & 3,224 & 17.8 & 240 & 13.0 \\
\hline
\end{tabular}

SD; Standard deviation, NOS; Not otherwise specified 
A. The trend of proportional frequencies each primary site in CIH-GCDB

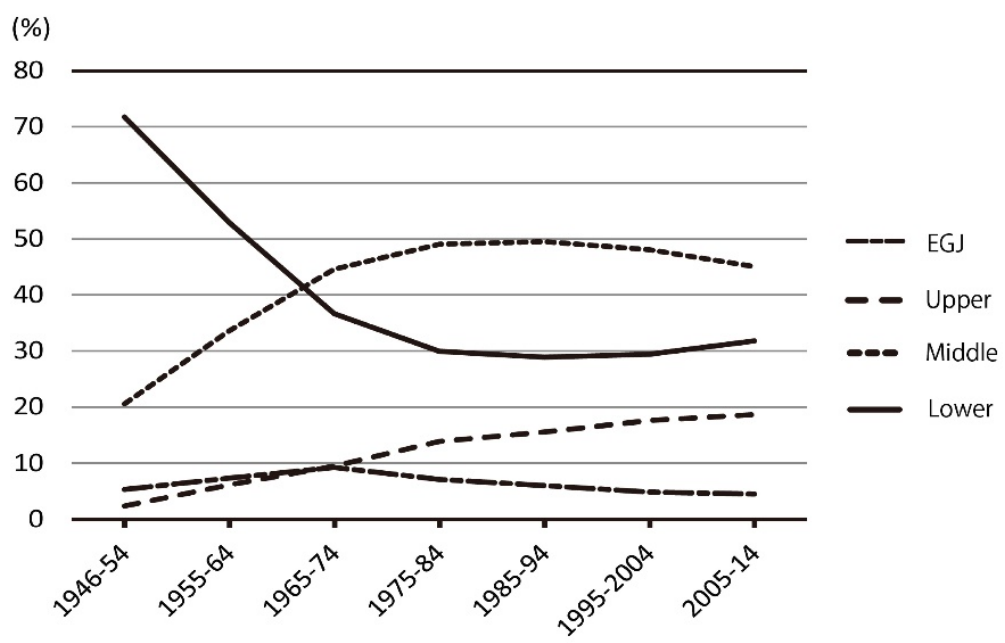

B. The trend of mean age and BMI in CIH-GCDB
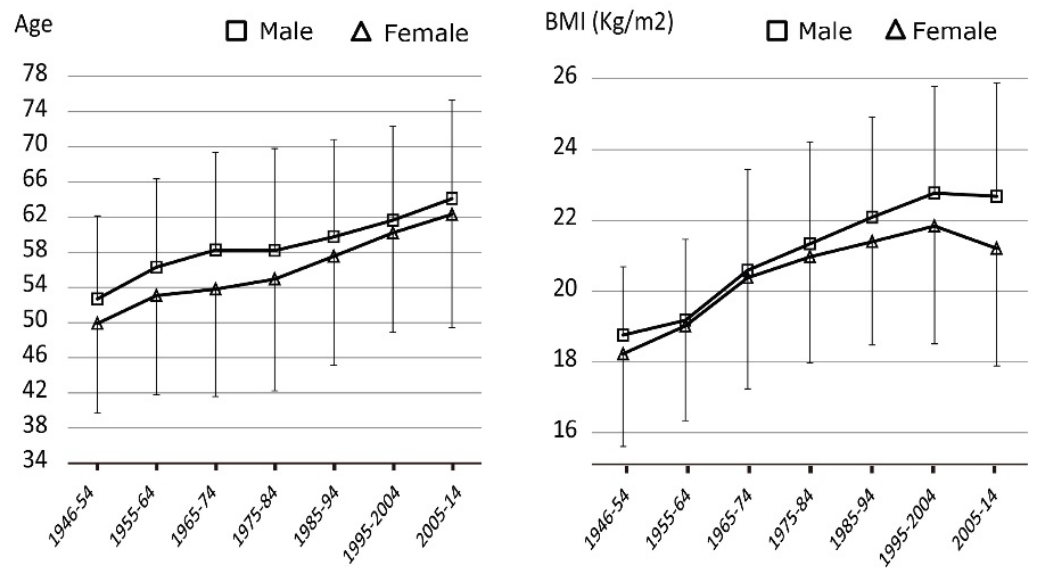

Figure 2: Primary site, patients age and BMI in CIH-GCDB. A: Time trends of in the relative frequencies of cancers arising at each primary site, based on the CIH-GCDB data. B: Time trends in age and BMI of patients with gastric cancer by gender.

\section{Discussion}

The main results of our study are threefold. First, in Japan, the incidence of gastric cancer in the lower third (antrum or pylorus) of the stomach has been steadily decreasing up to 1985 , whereas that in the upper third excluding the EGJ has been steady increasing up to the present. Second, East Asians living in the United States showed a tumor location trend distinctly different from that of patients of other races living in the U.S.; their proportion of cardia cancers has not been increasing over last 15 years, unlike the trend for white and black patients. Lastly, in the Japanese population, older age, obesity, male gender and recent year of diagnosis were significant independent risk factors for upper third gastric cancer.
Whereas the incidence rate of a lot of malignant neoplasms has been rising in developed countries, these of gastric, hepatic or uterine cervix cancer showed decline tendency $(1,2,6,7)$. The principal reason has been thought to be attributed to improvements in general public health. Namely the etiology these neoplasms were strongly associated to prevalence of specific virus or bacterial infection, and the decreasing of incident rate and advances of hygienic environment were observed in developed countries. Among environmental factors associated with the risk of gastric cancer, some researchers have regarded the endemic of $\mathrm{H}$. pylori infection as one of the strongest carcinogenic factors $(8,32,33)$. The sero-prevalence rate of $\mathrm{H}$. pylori infection was approximately 40 to $70 \%$ in patients with gastric cancer in Asian countries (34), and the overall sero-prevalence rate has been decreasing with the time trend $(8,34,35)$. Improvements in living conditions, the water supply or sewage systems are strongly correlated with the declining prevalence of $\mathrm{H}$. pylori (34). The expansion of industrial refrigeration has reduced the need for salting and pickling for food preservation, and the development of transportation has allowed distribution of fresher products to consumers (3). It has also become easy for people to include potentially protective factors such as vitamins $A, C$, and $E$ in their diet throughout the year (9-11), which may counteract carcinogenesis in the stomach linked to intake of $\mathrm{N}$-nitroso compounds in smoked or grilled meat $(36,37)$. The decline in the incidence of gastric cancer in Japan has been attributed to the overall improvement of public health accompanying the high economic growth following the severe poverty after World War II. Significantly, however, our results indicate that the above factors have been particularly associated with cancer in the antrum or pylorus of the stomach, rather than with gastric cancer as a whole. The number of patients with cancer in the upper third of the stomach has, in fact, been increasing over time, and therefore it can be considered that the risk factors for adenocarcinoma in the upper third are differ from those for cancer in the lower third. In term of histopathological type that has strong association with primary site arising adenocarcinoma, the fact that the proportion of signet 


\section{A. All patients}

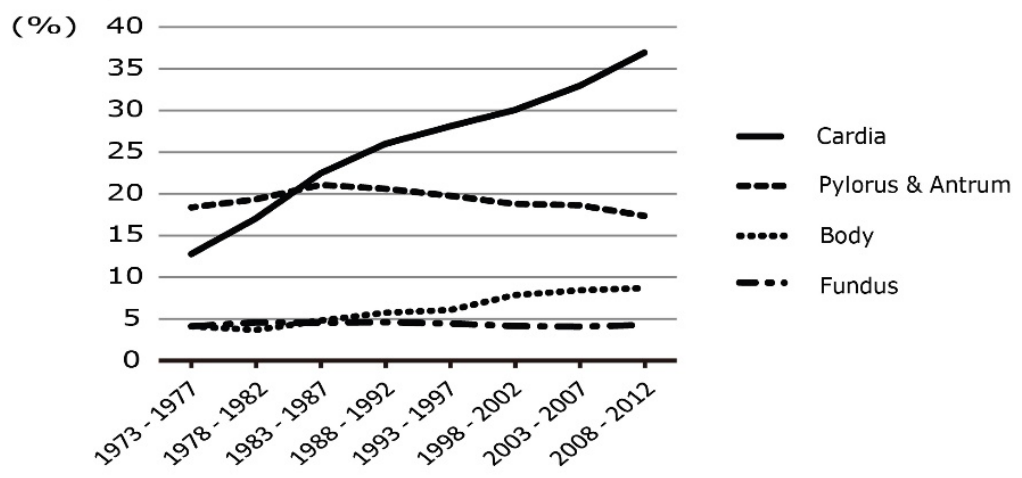

\section{B. Western population (White \& Black)}

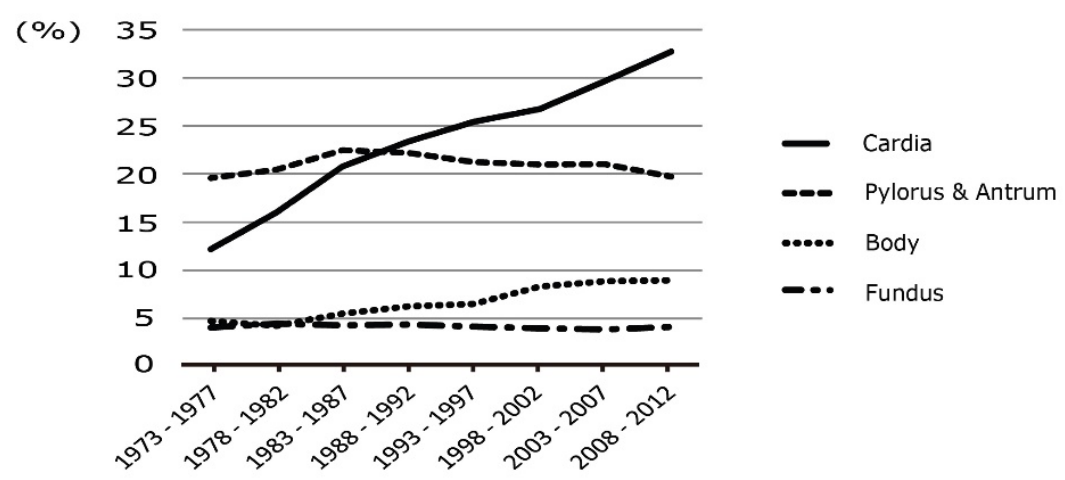

\section{East-Asian population (Chinese, Korean \& Japanese)}

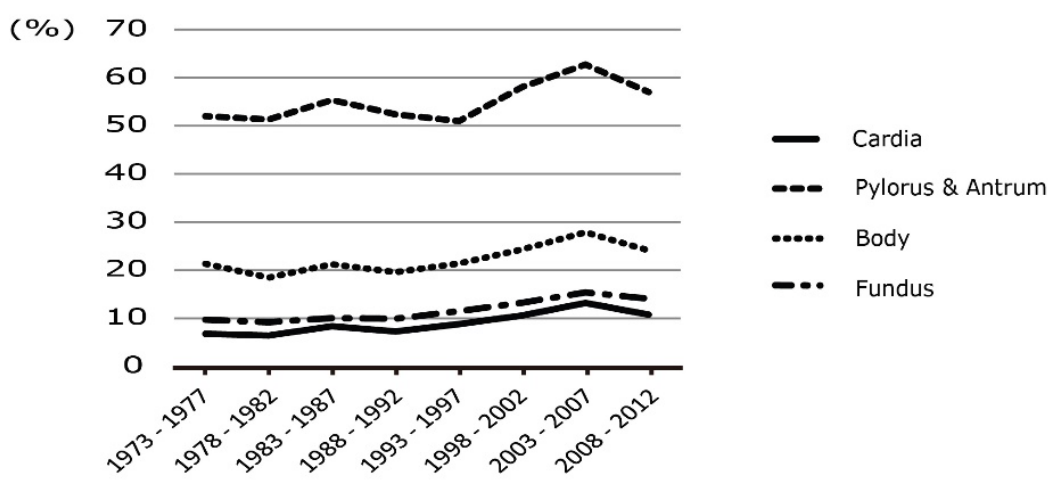

Figure 3: Time trends in the relative frequencies of cancers arising at each primary site, based on the SEER database. A: Time trend of proportional frequency for patients overall. B: Time trend of proportional frequency for Western (White or Black) patients overall. C: Time trend of proportional frequency for East Asian (Chinese, Korean and Japanese) patients

ring cell carcinoma has been rapidly increasing from early to middle period was not inconsistent with this sift of cancer location (Table 1).

From a physician's viewpoint, the current trend suggests that in East Asian populations a larger number of patients will need to be treated for cancer in the upper third of the stomach as time passes. In addition, as the proportion of obese and elderly patients will continue to increase in the near future, treatment of gastric cancer may become more difficult than it has been in the past. In this connection, a crucial difference between Japanese and Western patients is that the incidence of adenocarcinoma at the EGJ has remained consistently low in Japan for the last 70 years. Despite the marked increase of EGJ adenocarcinoma in Western patients documented in the SEER data and previous studies, the proportion of EGJ cancer in East Asians in the SEER has remained consistently low. Considering the trends evident in the two databases, it seems unlikely that the incidence of adenocarcinoma in the EGJ will increase rapidly in East Asian countries as a result of westernization in the near future.

This large-scale database study has some limitations. First, there is the difficulty in classifying adenocarcinoma as being present in the upper third, cardia or EGJ. In general, two types of adenocarcinoma can arise in the EGJ; one is derived from the fundic glands of the stomach, and the other from Barrett's epithelium. These two cancers ought to be essentially distinguished from each other, i.e. upper gastric cancer with esophageal invasion, and lower esophageal cancer with gastric invasion. However, in most cases, it is clinicopathologically difficult to identify whether the origin of a neoplasm is the gastric gland or the metaplastic columnar epithelium of the esophagus. Therefore, both gastric cancer with esophageal invasion and adenocarcinoma from Barrett's esophagus have been registered under the same category in all clinical databases. In addition, the Japanese definition of cancer in cardia is a slightly different from that of ICD-10 (Supplemental figure 1). Second, the SEER database contains no information about the lifestyle of the East Asian population, such as how long they have lived in the US or the types of foods they usually eat. Therefore, unknown or unmeasurable - but important - potential confounders might be overlooked. Another problem is that there is no guarantee that patients entered in the CIH-GCDB are a representative sample of Japanese patients with gastric cancer. The $\mathrm{CIH}$ GCDB is a database representing patients seen at a single institution, although the hospital handles the highest volume of cancer patients in Japan and the 
registration system has been established for nearly 70 years. The multi-center national cancer database system in Japan is still in its early stages and is tightly restricted to access for general researchers. Therefore, using the CIH-GCDB was the best resource for addressing our research aims, enabling us to analyze a large number of patients over a long time period.

In conclusion, our findings suggest that cancer in the lower third of the stomach has been declining, whereas cancer in the upper third has been increasing in recent years in Japan. Unlike the situation in Western patients, currently there is no evidence of any increase of EGJ adenocarcinoma in the Japanese population. However, from a clinical viewpoint, it may become more difficult to treat gastric cancer in Japanese patients in comparison with the past, in view of the increase of elderly and obese patients presenting with adenocarcinoma in the upper third of the stomach.

\section{Abbreviations}

CIH-GCDB: Gastric Cancer Database at the Cancer Institute Hospital

Results

SEER: Surveillance, Epidemiology, and End

H. pylori: Helicobactor pylori

EGJ: esophago-gastric junction

ICD-O-3: International Classification of Diseases for Oncology, 3rd edition

(JGCA)

JGCA: Japanese Gastric Cancer Association

BMI: body mass index

AJCC: American Joint Committee on Cancer

\section{Supplementary Material}

Supplementary figure 1.

http://www.jcancer.org/v08p1935s1.pdf

\section{Acknowledgements}

We would like to thank Mrs. Yoshiko Kobayashi for management of the CIH-GCDB system and her suggestions for our research. This study was supported, in part, by a grant-in-aid of The Public Trust Fund For Clinical Cancer Research.

\section{Competing Interests}

None to declare

\section{References}

1. Jemal A, Bray F, Center MM, Ferlay J, Ward E, Forman D. Global cancer statistics. CA Cancer J Clin 2011;61:69-90.

2. AmericanCancerSociety. Global Cancer Facts \& Figures 3rd Edition. http://wwwcancerorg/research/cancerfactsstatistics/global 2013:Accessed in 10th November 2015.

3. Howson $\mathrm{CP}$, Hiyama $\mathrm{T}$, Wynder EL. The decline in gastric cancer: epidemiology of an unplanned triumph. Epidemiol Rev 1986;8:1-27.
4. AmericanCancerSociety. Cancer Facts \& Figures 2015. http://wwwcancerorg/research/cancerfactsstatistics/cancerfactsfigures2015 /index 2015.

5. Malvezzi M, Bonifazi M, Bertuccio P et al. An age-period-cohort analysis of gastric cancer mortality from 1950 to 2007 in Europe. Ann Epidemiol 2010;20:898-905.

6. Vital_Statistics_Japan_Ministry_of_Health LaW. Cancer Registry and Statistics. Cancer Information Service, National Cancer Center, Japan. http://ganjohojp/reg_stat/statistics/dl/indexhtml 2015:Accessed in 10th November 2015.

7. World_Health_Organization. GLOBOCAN 2012: Estimated Cancer Incidence, Mortality and Prevalence Worldwide in 2012. http://globocaniarcfr/Defaultaspx 2012:Accessed in 10th November 2015.

8. Kamada $\mathrm{T}$, Haruma $\mathrm{K}$, Ito $\mathrm{M}$ et al. Time Trends in Helicobacter pylori Infection and Atrophic Gastritis Over 40 Years in Japan. Helicobacter 2015;20:192-8.

9. Galanis DJ, Kolonel LN, Lee J, Nomura A. Intakes of selected foods and beverages and the incidence of gastric cancer among the Japanese residents of Hawaii: a prospective study. Int J Epidemiol 1998;27:173-80.

10. Shimazu T, Wakai K, Tamakoshi A et al. Association of vegetable and fruit intake with gastric cancer risk among Japanese: a pooled analysis of four cohort studies. Annals of oncology: official journal of the European Society for Medical Oncology / ESMO 2014;25:1228-33.

11. Hirayama T. Epidemiology of stomach cancer in Japan. With special reference to the strategy for the primary prevention. Japanese journal of clinical oncology 1984;14:159-68.

12. Katanoda K, Hori M, Matsuda T et al. An updated report on the trends in cancer incidence and mortality in Japan, 1958-2013. Japanese journal of clinical oncology 2015;45:390-401.

13. Gonzalez CA, Jakszyn P, Pera G et al. Meat intake and risk of stomach and esophageal adenocarcinoma within the European Prospective Investigation Into Cancer and Nutrition (EPIC). J Natl Cancer Inst 2006;98:345-54.

14. Engel LS, Chow WH, Vaughan TL et al. Population attributable risks of esophageal and gastric cancers. J Natl Cancer Inst 2003;95:1404-13.

15. Matsuda A, Matsuda T, Shibata A et al. Cancer incidence and incidence rates in Japan in 2008: a study of 25 population-based cancer registries for the Monitoring of Cancer Incidence in Japan (MCIJ) project. Japanese journal of clinical oncology 2014;44:388-96.

16. Blot WJ, Devesa SS, Kneller RW, Fraumeni JF, Jr. Rising incidence of adenocarcinoma of the esophagus and gastric cardia. JAMA 1991;265:1287-9.

17. Botterweck AA, Schouten LJ, Volovics A, Dorant E, van Den Brandt PA. Trends in incidence of adenocarcinoma of the oesophagus and gastric cardia in ten European countries. Int J Epidemiol 2000;29:645-54.

18. Armstrong RW, Borman B. Trends in incidence rates of adenocarcinoma of the oesophagus and gastric cardia in New Zealand, 1978-1992. Int J Epidemiol 1996;25:941-7

19. Olefson S, Moss SF. Obesity and related risk factors in gastric cardia adenocarcinoma. Gastric cancer: official journal of the International Gastric Cancer Association and the Japanese Gastric Cancer Association 2015;18:23-32.

20. Hongo M, Nagasaki Y, Shoji T. Epidemiology of esophageal cancer: Orient to Occident. Effects of chronology, geography and ethnicity. J Gastroenterol Hepatol 2009;24:729-35.

21. Shibata A, Matsuda T, Ajiki W, Sobue T. Trend in incidence of adenocarcinoma of the esophagus in Japan, 1993-2001. Japanese journal of clinical oncology 2008;38:464-8.

22. Blaser MJ, Saito D. Trends in reported adenocarcinomas of the oesophagus and gastric cardia in Japan. Eur J Gastroenterol Hepatol 2002;14:107-13.

23. Liu Y, Kaneko S, Sobue T. Trends in reported incidences of gastric cancer by tumour location, from 1975 to 1989 in Japan. Int J Epidemiol 2004;33:808-15.

24. Strong VE, Song KY, Park $\mathrm{CH}$ et al. Comparison of gastric cancer survival following R0 resection in the United States and Korea using an internationally validated nomogram. Annals of surgery 2010;251:640-6.

25. Yao JC, Tseng JF, Worah $\mathrm{S}$ et al. Clinicopathologic behavior of gastric adenocarcinoma in Hispanic patients: analysis of a single institution's experience over 15 years. Journal of clinical oncology: official journal of the American Society of Clinical Oncology 2005;23:3094-103.

26. Yamada T, Yoshikawa $\mathrm{T}$, Taguri $\mathrm{M}$ et al. The survival difference between gastric cancer patients from the UK and Japan remains after weighted propensity score analysis considering all background factors. Gastric cancer: official journal of the International Gastric Cancer Association and the Japanese Gastric Cancer Association 2015.

27. Anderson WF, Camargo MC, Fraumeni JF, Jr., Correa P, Rosenberg PS, Rabkin CS. Age-specific trends in incidence of noncardia gastric cancer in US adults. Jama 2010;303:1723-8.

28. Camargo MC, Anderson WF, King JB et al. Divergent trends for gastric cancer incidence by anatomical subsite in US adults. Gut 2011;60:1644-9.

29. Nakajima T, Yamaguchi T, Sano T. Gastric Cancer Database in Cancer Institute Hospital of JFCR 1946 - 2007. Kanehara, Tokyo, Japan 2012;2.

30. Fritz A, Percy C, Jack A et al. International Classification of Diseases for Oncology; 3rd ed. Geneva: World Health Organization. 2000. http://apps.who.int/iris/bitstream/10665/96612/1/9789241548496_eng.pdf ?ua $=2$.

31. Japanese Gastric Cancer A. Japanese classification of gastric carcinoma: 3rd English edition. Gastric cancer: official journal of the International Gastric 
Cancer Association and the Japanese Gastric Cancer Association 2011;14:101-12.

32. Nakajima S, Nishiyama Y, Yamaoka M, Yasuoka T, Cho E. Changes in the prevalence of Helicobacter pylori infection and gastrointestinal diseases in the past 17 years. J Gastroenterol Hepatol 2010;25 Suppl 1:S99-S110.

33. Xia HH, Phung N, Altiparmak E, Berry A, Matheson M, Talley NJ. Reduction of peptic ulcer disease and Helicobacter pylori infection but increase of reflux esophagitis in Western Sydney between 1990 and 1998. Dig Dis Sci 2001;46:2716-23.

34. Fock KM, Katelaris $\mathrm{P}$, Sugano $\mathrm{K}$ et al. Second Asia-Pacific Consensus Guidelines for Helicobacter pylori infection. J Gastroenterol Hepatol 2009;24:1587-600.

35. Kobayashi T, Kikuchi S, Lin $\mathrm{Y}$ et al. Trends in the incidence of gastric cancer in Japan and their associations with Helicobacter pylori infection and gastric mucosal atrophy. Gastric cancer: official journal of the International Gastric Cancer Association and the Japanese Gastric Cancer Association 2004;7:233-9.

36. Sobala GM, Schorah CJ, Sanderson M et al. Ascorbic acid in the human stomach. Gastroenterology 1989;97:357-63.

37. Keszei AP, Goldbohm RA, Schouten LJ, Jakszyn P, van den Brandt PA. Dietary $\mathrm{N}$-nitroso compounds, endogenous nitrosation, and the risk of esophageal and gastric cancer subtypes in the Netherlands Cohort Study. Am J Clin Nutr 2013;97:135-46. 